\title{
Commentary: Is radiation needed after resecting an early-stage small cell lung cancer?
}

\author{
Melissa Taylor, MD, and Ikenna Okereke, MD
}

\author{
From the Division of Cardiothoracic Surgery, University of Texas Medical Branch, Galveston, Tex. \\ Disclosures: Authors have nothing to disclose with regard to commercial support. \\ Received for publication Aug 19, 2019; accepted for publication Aug 20, 2019; available ahead of print Oct 9. \\ 2019 \\ Address for reprints: Ikenna Okereke, MD, Thoracic Surgery, University of Texas Medical Branch, 301 Univer- \\ sity Blvd, Galveston, TX 77555 (E-mail: ikokerek@utmb.edu). \\ J Thorac Cardiovasc Surg 2019;158:1678 \\ $0022-5223 / \$ 36.00$ \\ Copyright (c) 2019 by The American Association for Thoracic Surgery \\ https://doi.org/10.1016/j.jtcvs.2019.08.092
}

Lung cancer is the leading cause worldwide of cancerrelated deaths. Small cell lung cancer (SCLC) makes up $15 \%$ of all lung cancer cases, but its aggressiveness is distinguished by rapid progression and early dissemination. ${ }^{1}$ In the 1970 s, it became a mostly nonsurgical disease due to its typical metastatic presentation and overall survival of less than $5 \%$ at 5 years. $^{2}$ Advancement in diagnostic modalities and the advent of minimally invasive approaches to resection have led to a re-evaluation of the role of surgery in early-stage disease. Over time, more surgery for SLCL has been performed. Retrospective analyses have shown that patients with early-stage disease have an overall 5 -year survival of $52 \%$ after complete resection. ${ }^{3}$

The role of radiation in adjuvant treatment of early disease has been controversial. In postoperative patients with no nodal disease, previous studies have been equivocal regarding the benefit of radiation. This article by Engelhardt and colleagues ${ }^{4}$ sought to answer this question with a retrospective review of the National Cancer Database, examining early-stage SCLCs with negative nodal status and comparing overall survival with and without adjuvant radiation. In their study, 1617 patients were ultimately included, but only $146(9.0 \%)$ received adjuvant thoracic radiation. The median survival did not improve with radiation, even after performing propensity matching analyses on various subgroups within the cohort.

There are several caveats that must be considered when interpreting this conclusion: (1) Only $9 \%$ of patients received radiation. (2) This database does not include approximately $20 \%$ of cancer cases nationwide, and there four percent of patients had no lymph node sampling. (4) There was variability in the technique used for surgical resection, varying between lobar and sublobar resection. (5) The patients who received adjuvant chemotherapy had varying regimens. (6) There were some results that were difficult to explain, such as high-volume centers having may be a systematic bias in the excluded cases. (3) Forty-

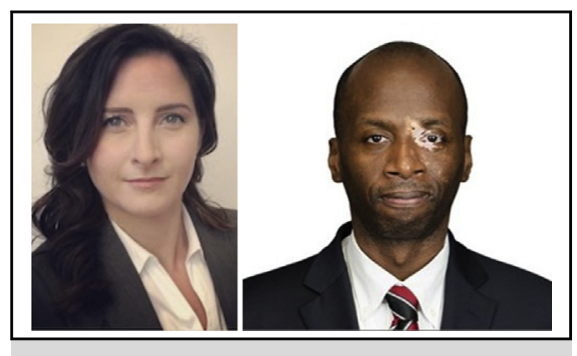

Melissa Taylor, MD, and Ikenna Okereke, MD

Central Message

Adjuvant radiation after complete resection for early-stage small cell lung cancer improves locoregional recurrence but not overall survival.

See Article page 1665. worse outcomes, which suggests that there may have been uncaptured confounders that could have affected all outcomes. (7) The overall number of patients included was relatively low.

Despite these limitations, their study addressed an important question and is useful among other studies that have investigated the role of adjuvant radiation therapy after resection of early-stage SCLC. A multi-institutional study would be able to address many of the aforementioned points. As it has been shown that lobectomy is associated with a better 5 -year survival than sublobar resection, ${ }^{5}$ the surgical conduct could be standardized across all participating centers. The chemotherapy regimens could be consistent, and all patients would be required to have lymph node sampling. Until a trial like this is performed, the utility of adjuvant radiation for these patients will continue to be debated.

\section{References}

1. Zhang S, Sun X, Sun L, Xiong Z, Ma J, Han C. Benefits of postoperative thoracic radiotherapy for small cell lung cancer subdivided by lymph node stage: a systematic review and meta-analysis. J Thorac Dis. 2017;9:1257-64.

2. Jackman D, Johnson B. Small-cell lung cancer. Lancet. 2005;366:1385-96.

3. Lim E, Belcher E, Yap Y, Nicholson AG, Goldstraw P. The role of surgery in the treatment of limited disease small cell lung cancer: time to reevaluate. J Thorac Oncol. 2008;3:1267-71.

4. Engelhardt K, Coughlin J, DeCamp MM, Denlinger CE, Meyerson SL, Bharat A, et al. Survival after adjuvant radiation therapy in localized small cell lung cancer treated with complete resection. J Thorac Cardiovasc Surg. 2019;158:1665-77.e2.

5. Combs S, Hancock J, Boffa D, Decker RH, Detterbeck FC, Kim AW. Bolstering the case for lobectomy in stages I, II, and IIIA small-cell lung cancer using the national cancer database. J Thorac Oncol. 2015;10:316-23. 